\title{
Patient factors relating to detection of posttraumatic stress disorder in Department of Veterans Affairs primary care settings
}

\author{
Kathryn M. Magruder, MPH, PhD; ${ }^{*}$ Derik E. Yeager, MBS \\ Mental Health Service, Ralph H. Johnson Department of Veterans Affairs Medical Center, Charleston, SC; Department \\ of Psychiatry and Behavioral Sciences and Department of Biostatistics, Bioinformatics, and Epidemiology, Medical \\ University of South Carolina, Charleston, SC
}

\begin{abstract}
We examined the impact of patient-level factors on provider recognition of posttraumatic stress disorder (PTSD). Analyses were based on a random sample of 1,079 consenting patients who had an outpatient visit at any of four southeastern Department of Veterans Affairs hospitals in 1999. We collected data on PTSD symptoms, sociodemographics, functional status, medical record diagnoses, and independent PTSD diagnostic assessments for 888 patients. Complete and usable data were available for 819 patients. A total of 98 patients (12\%) met criteria for PTSD, and of these, 42 (43\%) were correctly classified as such by their provider. Results indicate that age (50-64), war-zone service, worse functioning on the 36-Item Short Form Health Survey role emotional subscale, a diagnosis of musculoskeletal pain, a greater percentage of persistent reexperiencing or avoidance/numbing symptoms, and a previously diagnosed substance use disorder were all independently related to provider recognition of PTSD. Knowledge of these factors may help inform providers and direct improved screening and case finding.
\end{abstract}

Key words: detection, diagnosis, posttraumatic stress disorder, primary care, provider recognition, PTSD, rehabilitation, screening, VA, veterans.

\section{INTRODUCTION}

Primary care has been termed the "de facto" mental health treatment system because more people with mental disorders receive treatment in general medical settings than in mental health specialty settings [1-2]. Ironically, while general medical settings are the primary venue for treating mental disorders, a very large percentage of such disorders go unrecognized by primary care providers and therefore go untreated. Some reports suggest that $<50$ percent of those with depression are so diagnosed in primary care settings [3-5]. While most studies have been on recognition and treatment of depression in primary care settings, several recent studies have begun to focus on other mental disorders that are potentially treatable in primary care, including posttraumatic stress disorder (PTSD). These studies have shown that, as with depression, PTSD has a relatively high prevalence in primary

Abbreviations: ANOVA $=$ analysis of variance, CAPS $=$ Clinician-Administered PTSD Scale, CI = confidence interval, DSM-IV $^{\circledR}=$ Diagnostic and Statistical Manual of Mental Disorders-Fourth Edition, FY = fiscal year, ICD-9 = International Classification of Diseases-9th Revision, IRB = institutional review board, OR = odds ratio, PCL-C $=$ PTSD ChecklistCivilian version, PTSD = posttraumatic stress disorder, SF-36 ${ }^{\circledR}=$ 36-Item Short Form Health Survey, VA = Department of Veterans Affairs, VAMC = VA medical center.

*Address all correspondence to Kathryn M. Magruder, MPH, PhD; Mental Health Service, Ralph H. Johnson VAMC, 109 Bee St, Charleston, SC 29401; 843-789-7084; fax: 843-937-6100. Email: kathryn.magruder@va.gov DOI: 10.1682/JRRD.2007.06.0091 
care, ranging from 6 to 20 percent [6-10], and is typically associated with high levels of social and occupational disability, medical and psychiatric comorbidity, and services use [11-30].

Two recent studies of PTSD in primary care have found considerable discrepancy between those who meet criteria for diagnosis and those who are formally diagnosed. One of these studies was conducted in four Department of Veterans Affairs (VA) primary care clinics and found that for patients who met Diagnostic and Statistical Manual of Mental Disorders-Fourth Edition $\left(\mathrm{DSM}-\mathrm{IV}^{\circledR}\right.$ ) criteria for PTSD (based on the ClinicianAdministered PTSD Scale [CAPS], an assessment considered the gold standard for PTSD diagnosis), 12-month record reviews indicated that providers identified only 46.5 percent as having PTSD and only 47.7 percent had used mental health specialty services [10]. The other study was conducted in Israeli primary care settings with even more dismal results: of those who met criteria for PTSD, only 2 percent were so diagnosed by their primary care physician, though considerably more were recognized as being "distressed" [9].

Given that correct diagnosis is the starting point of any successful treatment and rehabilitation program, we must try and understand the factors that influence underrecognition. The somatic presentation of many primary care patients may interfere with physicians' diagnosis of psychiatric disorders [31]. Primary care providers may investigate somatic symptoms as presumptive evidence of medical illness rather than consolidating the evidence in the context of less prominent psychiatric symptoms. Conflicting findings suggest that (at least for depression) the presence of pain and poor functioning due to pain may increase the likelihood that depression will be diagnosed [32].

In addition to the pain and depression recognition findings, the relationship between pain and PTSD recognition should be investigated because pain has been shown to be a correlate of PTSD in many studies [33-35]. After a careful review of the literature on the co-occurrence of pain and PTSD, Otis et al. found that these conditions "co-occur at a high rate and may interact in such a way as to negatively impact the course of the disorder" [33]. Though the exact mechanisms explaining this interaction are as yet not fully understood, several theoretical models have been proposed. The mutual maintenance and the shared vulnerability models dominate the literature [3336]; however, new theoretical models continue to emerge
$[33,37]$. The mutual maintenance model posits that factors related to each condition (e.g., avoidance to minimize pain and distressing thoughts, selective focus on pain and PTSD-related stimuli) reinforce the maintenance of the other condition. The shared vulnerability model posits that common vulnerabilities underlie both pain and PTSD. Not antithetical to either of these theories, several studies have found that the relationship between PTSD and pain is mediated by depression [3839]. Intriguingly, a recent study by Shipherd et al. showed that patients with PTSD who also had high selfrated levels of pain reported a reduction in pain levels following intensive outpatient PTSD treatment [40]. This study supports the existence of either shared mechanisms (which are both addressed in PTSD treatment) for PTSD and pain or mutually reinforcing behaviors (which are again addressed in PTSD treatment). More definitive tests of these theories await longitudinal study to disentangle the time relationships between pain conditions and PTSD symptoms [34].

Particularly for non-mental health providers, the challenges to correct diagnosis of psychiatric illness and PTSD in particular are many and are evident at a number of different levels. In addition to the patient's presentation, providers are influenced by many issues, not the least of which are their own knowledge and capabilities, as well as system-level factors, such as presence of ancillary providers, scheduling, and reimbursement. Though these factors are important, in this article we spotlighted patient-level factors, with a focus on presentations that clinicians may overlook. We focused on patient-level factors that would be readily available to a busy clinician and that could influence his or her decision to pursue a PTSD diagnosis. These factors included age, sex, race/ ethnicity, education, war-zone exposure, and clinical diagnoses. We used electronic medical records to establish the presence of preexisting clinical diagnoses, such as pain-related diagnoses and psychiatric diagnoses. In addition, we examined 36-Item Short Form Health Survey (SF-36 ${ }^{\circledR}$ ) scores and PTSD Checklist-Civilian version (PCL-C) scores within criterion clusters as indicators of potential patient presentation to the clinician. We reasoned that clinicians would be reasonably sensitive to their patients' presentations in these domains and these presentations could influence pursuit of a PTSD diagnosis.

Our overall purpose was to elucidate patient-level factors that may influence providers in the recognition of PTSD. We focused on sociodemographic variables, patient 
functioning (especially pain-related functioning), comorbid psychiatric conditions and medical diagnoses (in particular pain-related diagnoses), and PTSD symptom clusters. This project and its parent project were approved by the institutional review board (IRB) of the Medical University of South Carolina; additionally, the parent project was approved by appropriate IRBs at the VA medical centers (VAMCs) in Columbia, South Carolina; Tuscaloosa, Alabama; and Birmingham, Alabama.

\section{METHODS}

\section{Study Population}

The current analysis was based on data gathered from patients at four VAMCs in the southeast region of the United States. Eligible patients were identified from among the 229,780 veterans who had had a primary care visit during fiscal year (FY) 1999. Patients with known dementia, octogenarians, and nonagenarians were excluded because of concern over their ability to recall information critical to the study.

Two study samples were recruited. Patients in group 1 were randomly selected from those who had an outpatient visit in FY 1999 at one of the four study hospitals. See Magruder et al. for a more detailed explanation of the sampling strategy $[10,41]$. Patients in group 2 consisted of an oversample of female patients only. These women came from the same primary care clinics. See Grubaugh et al. for more details of the oversampling procedure [42]. Aside from the oversampling, consent and study procedures were identical for the two groups of patients.

At the time of the clinic visit, we provided further explanation of the study to targeted patients, including the fact that this was a study of stress-related disorders in primary care. We obtained written informed consent before study participation. At this clinic visit, we collected sociodemographic information and administered the PCL-C. Patients were told that they would be called by telephone for a follow-up interview.

The telephone interview took place within 2 months of the clinic interviews. Clinicians, trained master's level and above, administered the Trauma Assessment (to assess for PTSD criterion A) and the CAPS. CAPS interviewers were blind to PCL-C screening results. Telephone interviewers were the same for patients in both groups 1 and 2, and interviewers were not informed as to which subjects had been identified by the oversampling procedure.

In addition to the data generated by the clinic interview and the telephone diagnostic interview, we downloaded International Classification of Diseases-9th Revision (ICD-9) diagnoses from the Veterans Integrated Service Network 7 corporate database for a 2-year period, with the clinic interview as the midpoint.

\section{Analyses}

Using the CAPS as a gold standard, we classified patients with current PTSD into two groups based on provider recognition. Provider recognition was established by presence of the ICD-9 code for PTSD (309.81) in the patient's electronic medical record. A total of 42 patients met this condition and were considered "recognized"; the remaining 56 CAPS-positive patients were classified as "under-recognized" because no ICD-9 code for PTSD was present in their medical record. For all analyses, provider-recognition status was the dependent variable. Multivariate analysis of variance (ANOVA) and logistic models included age, race, sex, and war-zone exposure as independent covariates.

Sociodemographic variables were tested across provider-recognition groups with chi-square analyses. We used ANOVA to compare self-reported health status information (SF-36 subscales) by provider-recognition groups. Logistic analyses produced unadjusted and adjusted odds ratios (ORs) that assessed the increased odds of provider recognition of PTSD in the presence of clinical pain indicators (electronic medical ICD-9 records, Table 1), preexisting comorbid psychiatric diagnoses (ICD-9 records), and PTSD symptom cluster dominance (derived from the PCL-C).

\section{Measures}

\section{Clinician-Administered PTSD Scale}

The CAPS is a structured clinical interview developed at the National Center for PTSD in 1990 to rate the frequency and intensity of the 17 symptoms of PTSD outlined in the DSM-IV, along with five associated features (guilt, dissociation, derealization, depersonalization, and reduction in awareness of surroundings) [43-45]. The CAPS has been shown to have strong interrater reliabilities (0.92-0.99) for each of the three PTSD symptom clusters. The CAPS has a high degree of internal consistency (0.73-0.85), is highly correlated with the Mississippi 
JRRD, Volume 45, Number 3, 2008

Table 1.

Description of pain-related diagnoses by chart-recorded International Classification of Diseases-9th Revision (ICD-9) code.

\begin{tabular}{llc}
\hline Pain Category ICD-9 Code & Description
\end{tabular}

Back 724.0x, 724.1, 724.2, 724.3, 724.4, 724.5, 724.6, 724.7x, 724.8, 724.9

Chest 307.81, 346.0/346.99, 784.0, 786.5, 786.50, 786.51, 786.52, 786.59

Musculoskeletal 274.0/274.99, 524.60/524.69, 714.0/715.99, 716.50/716.59, 723.1, 726.0/726.99, 728.9, 729.1, 729.5, 737.30/737.39, 716.90/716.99, 719.40/719.49, 721.0/721.99, 722.70/722.99, 723.2, 727.2

Neurological 350.1, 353.6, 354.2, 354.3, 354.4, 356.9, 531.90/531.99, 729.2

Other

307.80, 307.89, 350.2, 379.91, 564.1, 625.2, 625.3, 784.1, 789.00/789.09
Back disorder (NEC/NOS), spinal stenosis (NEC/NOS/ thoracic/lumbar/other site), pain in thoracic spine, lumbago, sciatica lumbosacral neuritis NOS, backache NOS, disorders of sacrum, disorders of coccyx, disorder of coccyx NOS, hypermobility of coccyx, disorder of coccyx NEC, other back symptoms, back disorder NOS.

Chest pain, chest pain NOS, precordial pain, painful respiration, chest pain NEC.

Temporomandibular joint disorder, other inflammatory polyarthropathy, general osteoarthrosis, polyarthritis NOS, cervicalgia, peripheral enthesopathies, muscle/ ligament disorder NOS, myalgia and myositis NOS, pain in limb, scoliosis, arthropathy NOS, pain in joint, spondylosis etc., disc disorder with myelopathy, cervicocranial syndrome, occupational bursitis.

Trigeminal neuralgia, phantom limb (syndrome), ulnar nerve lesion, radial nerve lesion, causalgia upper limb, idio peripheral neuropathy NOS, stomach ulcer NOS, neuralgia/neuritis NOS.

Psychogenic pain NOS, psychogenic pain NEC, atypical facial pain, pain in or around eye, irritable bowel syndrome, mittelschmerz, dysmenorrhea, throat pain, abdominal pain.

NEC = not elsewhere classifiable, NOS = not otherwise specified.

Scale for Combat-Related PTSD (0.70-0.91) and revised Minnesota Multiphasic Personality Inventory Keane PTSD subscale (0.77-0.84), and has good diagnostic utility when compared with the Structured Clinical Interview for the DSM-IV Axis I disorders PTSD module [44]. It also has excellent correspondence with the PCL-C (area under the curve $=88.2 \%$ ) [44]. Magruder et al. conducted a random sample of interviews (8\%) by speakerphone to assess interrater reliability and found that raters were 100 percent concordant for PTSD diagnosis on the CAPS [10]. Frequency and intensity information was collected for each of these symptoms within the context of lifetime and current (within the past month) patient experiences. Using the frequency/intensity CAPS scoring rule, symptoms were coded as present if frequency $\geq 1$ and intensity $\geq 2$ [43]. PTSD caseness was established if patients satisfied DSM-IV criteria B, C, and D and the duration of symptoms was $>1$ month.

\section{PTSD Checklist-Civilian Version}

The PCL-C is a brief self-report inventory that assesses the 17 symptoms of PTSD [46]. Psychometric data show that the PCL-C has good correspondence with the CAPS [46-48]. The PCL-C includes a series of 17 questions about symptoms or signs of PTSD. Each positive response is worth 5 points, with a maximum score of 85. A score of 50 (out of a maximum of 85 points) is the current recommended cutoff suggestive of PTSD.

The 17 DSM-IV symptoms from the PCL-C were grouped into three clusters corresponding with DSM-IV criteria B, C, and D. For each patient, ratings for each question were summed (within each cluster) and divided by their total PCL-C score. Tertiles were assigned based on the distribution of values for all patients within each cluster. Our purpose was to measure the relative contribution of each cluster in order to determine which cluster(s) played the more dominant role in provider recognition. 


\section{6-Item Short Form Health Survey}

The SF-36 is a self-report, generic measure of functional health status that assesses two factor analytically derived dimensions (physical health and mental health) with multiple subscales: physical functioning, role functioning limited by health, energy and fatigue, pain, general health, role functioning limited by emotional problems, emotional well-being, and social functioning. The SF-36 discriminates severity of functional impairment across a variety of disease states, such as hypertension, arthritis, gastrointestinal disorders, and myocardial infarction [4950]. In a preliminary study, this measure was shown to be associated with PTSD symptoms and was sensitive to change in response to treatment for PTSD symptoms [51]. The SF-36 raw scores were transformed to a 0 to 100 scale according to the formulas for scoring and transforming in the SF-36 manual.

We were particularly interested in the SF-36 subscale "bodily pain," which is measured by two questions: "How much bodily pain have you had during the past 4 weeks?" and "During the past 4 weeks, how much did pain interfere with your normal work (including both work outside the home and housework)?” The responses to these items are used to create a single bodily pain variable, scaled to range from 0 (poor functioning) to 100 (excellent functioning) (see Ware for methods [52]).

\section{Clinical Pain}

Clinical pain was coded as present if at least one ICD-9 code with a pain feature (Table 1) was recorded in a patient's electronic medical record within the 2-year interval. Based on these diagnoses, we categorized clinical pain into five major types: back, chest, musculoskeletal, neurological, and other.

\section{Comorbid Psychiatric Conditions}

Psychiatric diagnoses from patient electronic medical records were grouped into depression, anxiety, and substance use disorder categories using ICD-9 codes. Conditions were classified as having been previously diagnosed if they occurred prior to the date of PTSD diagnosis. Patients not diagnosed with PTSD were assigned a date generated from diagnosed patients' data. This date was based on the average number of days from the baseline clinical interview to the date of PTSD clinical diagnosis. A code for presence of a "previously diagnosed comorbid" condition was then generated for patients not diagnosed with PTSD based on this date.

\section{RESULTS}

Overall, 1,474 patients were invited to participate and 1,079 (73.2\%) signed informed consent documents. Of these, 888 (82.3\%) completed the telephone interviews. Of the 819 patients with usable data relevant to these analyses, 98 were positive by CAPS for current PTSD. Of the 12 percent (98/819) of our sample that met criteria for PTSD based on the CAPS, 43 percent (42/98) were correctly classified (ICD-9 diagnosis) as such by their provider; 57 percent (56/98) did not receive an ICD-9 diagnosis of PTSD.

Table 2 shows the bivariate results for sociodemographic characteristics comparing patients who were correctly identified by their provider as having PTSD with those not so identified. Only age and war-zone experience were statistically significant. Recognition differed markedly by age, with patients between the ages of 50 and 64 more likely to be recognized than those in the younger and older age groups, $\chi^{2}(2,0.05)=7.49, p=0.024$. Of all the patients with PTSD, those who reported serving in a war zone were 3 times more likely to be recognized by their provider as patients that did not report serving in a war zone $(\mathrm{OR}=3.0,95 \%$ confidence interval $[\mathrm{CI}]=$ 1.1-7.9). No significant differences in recognition by race, sex, war era, educational attainment, employment status, or primary care site were noted.

Table 3 shows the results of functioning status as measured by the SF-36 related to provider recognition. In all domains except for general health, under-recognized patients had better functioning (higher scores); however, this result was only statistically significant for the role emotional subscale. Results were also not significant when we combined all domains into two composite scores (mental health and physical health). Further tests were conducted adjusting for age, race, sex, and warzone service. (Though race and sex were not significant in the bivariate analyses, we continued to control for them because of their clinical importance.) The role emotional subscale continued to be statistically significant, and the physical health composite approached significance $(p=0.054)$.

We were particularly interested in pain, because pain has been associated with both PTSD and depression. The SF-36 pain subscale items measure two very different dimensions: levels of pain and the effect of pain on functioning. Because these items could independently affect 
JRRD, Volume 45, Number 3, 2008

Table 2.

Sociodemographic characteristics by posttraumatic stress disorder recognition status. Data presented as $n$ (\%).

\begin{tabular}{|c|c|c|c|}
\hline Variable & $\begin{array}{c}\text { Provider Recognized } \\
(n=42)\end{array}$ & $\begin{array}{l}\text { Under-Recognized } \\
\qquad(n=56)\end{array}$ & $\chi^{2} \boldsymbol{p}$-Value \\
\hline $\begin{array}{l}\text { Age }^{*}(\mathrm{yr}) \\
<50 \\
\\
50-64 \\
65\end{array}$ & $\begin{array}{r}5(11.9) \\
30(71.4) \\
6(14.3)\end{array}$ & $\begin{array}{l}18(32.1) \\
26(46.4) \\
12(21.4)\end{array}$ & 0.024 \\
\hline $\begin{array}{l}\text { Race } \\
\text { Caucasian } \\
\text { African American }\end{array}$ & $\begin{array}{l}21(50.0) \\
21(50.0)\end{array}$ & $\begin{array}{l}32(57.1) \\
24(42.9)\end{array}$ & 0.483 \\
\hline $\begin{array}{l}\text { Sex } \\
\text { Male } \\
\text { Female }\end{array}$ & $\begin{array}{c}38(90.5) \\
4(9.5)\end{array}$ & $\begin{array}{l}45(80.4) \\
11(19.6)\end{array}$ & 0.169 \\
\hline $\begin{array}{l}\text { Education } \\
\text { High School Diploma } \\
\text { >High School Diploma }\end{array}$ & $\begin{array}{l}17(40.5) \\
25(59.5)\end{array}$ & $\begin{array}{l}23(41.1) \\
33(58.9)\end{array}$ & 0.953 \\
\hline $\begin{array}{l}\text { War Zone } \\
\text { Served in War Zone } \\
\text { Did Not Serve in War Zone }\end{array}$ & $\begin{array}{r}35(83.3) \\
7(16.7)\end{array}$ & $\begin{array}{l}35(62.5) \\
21(37.5)\end{array}$ & 0.024 \\
\hline $\begin{array}{l}\text { War Era } \\
\text { World War II } \\
\text { Korea } \\
\text { Vietnam } \\
\text { Persian Gulf }\end{array}$ & $\begin{aligned} 4 & (9.5) \\
3 & (7.1) \\
29 & (69.1) \\
6 & (14.3)\end{aligned}$ & $\begin{array}{l}6(10.7) \\
2(3.6) \\
31(55.4) \\
17(30.4)\end{array}$ & 0.260 \\
\hline $\begin{array}{l}\text { Site } \\
\text { Birmingham, Alabama } \\
\text { Tuscaloosa, Alabama } \\
\text { Charleston, South Carolina } \\
\text { Columbia, South Carolina }\end{array}$ & $\begin{array}{r}7(16.7) \\
8(19.1) \\
7(16.7) \\
20(47.6)\end{array}$ & $\begin{array}{r}9(16.1) \\
9(16.1) \\
17(30.4) \\
21(37.5)\end{array}$ & 0.466 \\
\hline
\end{tabular}

recognition, we examined each separately. Neither item was significantly related to recognition of PTSD.

In Table 4, we provide the results of our analysis of the relationship between pain-related diagnoses and provider recognition. Patients with at least one ICD-9 record of musculoskeletal pain were 3.8 times more likely to be recognized by their provider $(\mathrm{OR}=3.8,95 \% \mathrm{CI}=1.2$ 12.4). Diagnoses of other categories of pain (chest, back, neurological, and other) were not related to provider recognition. After adjustment for age, sex, race, and warzone service, patients with musculoskeletal pain were still more likely to have been recognized with PTSD by their provider.

Patients' responses on the PCL-C were grouped into PTSD symptom clusters corresponding to the $\mathrm{B}, \mathrm{C}$, and D
DSM-IV criteria. Table 5 shows that patients with a high percentage of their PCL-C score accounted for by cluster B questions (reexperiencing symptoms) were more apt to be recognized by their provider than those in the lowest two cluster B tertiles. Patients in the middle tertile for cluster D (symptoms of increased arousal) were also more apt to be recognized than those in the low or high cluster D tertiles. Adjustment for age, sex, race, and warzone service showed that patients in the upper two tertiles for both clusters B and D were more apt to have been recognized than patients in the lowest tertiles.

Table 6 demonstrates that patients identified as having PTSD by their provider were significantly more likely to have a previously diagnosed comorbid substance use disorder. The trend is similar for previously 
Table 3.

Functioning status by posttraumatic stress disorder recognition status. Data presented as mean \pm standard deviation.

\begin{tabular}{|c|c|c|c|c|c|c|}
\hline \multirow{2}{*}{ Scale } & \multirow{2}{*}{$\begin{array}{c}\text { Provider } \\
\text { Recognized } \\
(n=42)\end{array}$} & \multirow{2}{*}{$\begin{array}{l}\text { Under-Recognized } \\
\qquad(n=56)\end{array}$} & \multicolumn{2}{|c|}{ Univariate ANOVA } & \multicolumn{2}{|c|}{ Multivariate ANOVA } \\
\hline & & & F-Value & $p$-Value & F-Value & $p$-Value \\
\hline General Health & $56.1 \pm 11.9$ & $54.0 \pm 13.6$ & 0.91 & 0.580 & 0.83 & 0.660 \\
\hline Vitality & $27.1 \pm 16.5$ & $32.1 \pm 19.8$ & 0.71 & 0.758 & 0.75 & 0.715 \\
\hline Physical Functioning & $38.9 \pm 25.0$ & $44.4 \pm 31.0$ & 1.12 & 0.347 & 0.79 & 0.703 \\
\hline Social Functioning & $42.7 \pm 24.8$ & $50.2 \pm 30.7$ & 1.05 & 0.420 & 1.32 & 0.227 \\
\hline Role Emotional & $17.1 \pm 27.0$ & $37.7 \pm 43.5$ & 3.88 & 0.012 & 3.01 & 0.039 \\
\hline Bodily Pain & $27.7 \pm 24.6$ & $36.3 \pm 29.5$ & 0.77 & 0.613 & 1.12 & 0.365 \\
\hline $\begin{array}{l}\text { Physical Health } \\
\text { Composite Score }\end{array}$ & $113.3 \pm 54.8$ & $122.9 \pm 64.7$ & 1.20 & 0.269 & 2.20 & 0.054 \\
\hline $\begin{array}{l}\text { Mental Health } \\
\text { Composite Score }\end{array}$ & $129.4 \pm 57.9$ & $171.4 \pm 101.0$ & 1.50 & 0.424 & 1.00 & 0.629 \\
\hline
\end{tabular}

Table 4.

Clinical pain diagnoses by posttraumatic stress disorder recognition status. Data presented as $n$ (\%).

\begin{tabular}{lcccc}
\hline Pain Category & $\begin{array}{c}\text { Provider Recognized } \\
(\boldsymbol{n}=\mathbf{4 2})\end{array}$ & $\begin{array}{c}\text { Under-Recognized } \\
(\boldsymbol{n}=\mathbf{5 6})\end{array}$ & OR (95\% CI) & $\begin{array}{c}\text { Adjusted OR* } \\
\mathbf{( 9 5 \%} \mathbf{C I})\end{array}$ \\
\hline Back & $18(42.9)$ & $19(33.9)$ & $1.46(0.64-3.33)$ & $1.76(0.73-4.23)$ \\
Chest & $10(23.8)$ & $8(14.3)$ & $1.88(0.67-5.26)$ & $3.18(0.92-11.04)$ \\
Musculoskeletal & $38(90.5)$ & $40(71.4)$ & $3.80(1.17-12.39)$ & $3.50(1.03-11.89)$ \\
Neurological & $5(11.9)$ & $5(8.9)$ & $1.38(0.37-5.11)$ & $1.62(0.41-6.32)$ \\
Other & $4(9.5)$ & $11(19.6)$ & $0.43(0.13-1.46)$ & $0.42(0.12-1.54)$ \\
Any & $39(92.9)$ & $47(83.9)$ & $1.75(0.63-9.83)$ & $2.61(0.63-10.75)$ \\
*Adjusted for age, race, sex, and war-zone experience. & & & \\
CI = confidence interval, OR = odds ratio. & & & \\
\hline \hline
\end{tabular}

Table 5.

Odds of posttraumatic stress disorder recognition by symptom cluster dominance.

\begin{tabular}{|c|c|c|}
\hline Variable & OR (95\% CI) & $\begin{array}{c}\text { Adjusted OR* } \\
(95 \% \mathrm{CI})\end{array}$ \\
\hline \multicolumn{3}{|l|}{ Cluster B } \\
\hline Lowest Tertile & 1 & 1 \\
\hline Middle Tertile & 3.52 (0.85-14.63) & 5.73 (1.12-29.37) \\
\hline Highest Tertile & $9.90(1.76-55.83)$ & $22.15(2.90-169.21)$ \\
\hline \multicolumn{3}{|l|}{ Cluster C } \\
\hline Lowest Tertile & 1 & 1 \\
\hline Middle Tertile & $0.93(0.25-3.41)$ & 2.03 (0.45-9.13) \\
\hline Highest Tertile & $1.83(0.44-7.58)$ & 3.61 (0.71-18.47) \\
\hline \multicolumn{3}{|l|}{ Cluster D } \\
\hline Lowest Tertile & 1 & 1 \\
\hline Middle Tertile & 4.31 (1.34-13.86) & $8.93(2.25-35.43)$ \\
\hline Highest Tertile & $3.44(0.69-17.20)$ & $8.58(1.35-54.57)$ \\
\hline
\end{tabular}

diagnosed comorbid depression and anxiety; however, these results are not statistically significant. Results do not change with adjusted logistic models (adjusting for age, race, sex, and war-zone service).

\section{DISCUSSION AND CONCLUSIONS}

Our findings indicate that providers were more apt to recognize as having PTSD those patients who were middleaged, had served in a war zone, had co-occurring musculoskeletal disorders, and had a preexisting diagnosed substance use disorder. In addition, providers were more likely to recognize patients who were emotionally distressed and whose symptoms were weighted more heavily in the B and D PTSD symptom clusters.

Providers may associate PTSD with middle age because most Vietnam war era veterans are in this age 
JRRD, Volume 45, Number 3, 2008

Table 6.

Preexisting comorbid psychiatric diagnoses by recognition status.

\begin{tabular}{lcc}
\hline \multicolumn{1}{c}{ Variable } & OR (95\% CI) & Adjusted OR* (95\% CI) $^{*}$ \\
\hline Major Depressive Disorder & $2.40(0.72-7.96)$ & $2.58(0.74-9.09)$ \\
Anxiety & $5.79(0.62-53.84)$ & $8.93(0.70-113.28)$ \\
Substance Abuse Disorders & $11.00(1.30-93.28)$ & $9.91(1.12-87.55)$ \\
\hline${ }^{*}$ Adjusted for age, race, sex, and war-zone experience. & & \\
CI = confidence interval, OR = odds ratio. & & \\
\hline \hline
\end{tabular}

group; however, when we examined war era by itself, it was not a significant factor in PTSD recognition. We should note that data for the present study were collected prior to the present conflicts in Iraq and Afghanistan. With new and younger veterans from the current conflicts now seeking VA care, providers may pay more attention to younger age groups. While the differences in recognition by sex were not significant, results were suggestive, with 73.3 percent $(11 / 15)$ of women being unrecognized compared with 54.2 percent (45/83) of men. The lack of race differences suggests that providers are focusing on symptom presentation and that symptom presentation is relatively uniform across races. We should also note that in this sample minorities were overwhelmingly African American, thus findings could be different for other ethnic/minority groups.

We were not surprised that providers were more apt to diagnose patients who served in a war zone because 47.5 percent of all VA patients report having served in a war zone and those that served in a war zone were 5 times more likely to develop PTSD [10]. This finding makes intuitive sense because these patients are more likely to have experienced combat exposure, which is the most common traumatic event for military veterans [53].

Based on previous findings for depression, we had expected pain and disability due to pain (as measured by the SF-36) to be related to provider recognition of PTSD but this was not the case. Interestingly, diagnoses related to musculoskeletal pain were related to recognition. These diagnoses include neck pain, limb/joint pain, rheumatoid arthritis, osteoarthrosis, myalgia, etc. Since musculoskeletal pain was significant even after controlling for age, race, sex, and war-zone exposure, it may be related to specific war injuries rather than general warzone experience.

Substance use disorders in particular are known to co-occur with PTSD; thus, we expected to find that providers were more apt to diagnose PTSD in patients with known substance abuse or dependence. Depression is also a common co-occurring disorder with PTSD, and indeed, our data trend in support of previously diagnosed comorbid depression being associated with PTSD recognition.

It makes sense that emotional functioning in our SF36 subscales was related to provider recognition. The role emotional subscale is composed of three yes/no questions: "During the past 4 weeks have you cut down the amount of time you spent on work or other activities as a result of any emotional problems (such as feeling depressed or anxious)?" "During the past 4 weeks have you accomplished less than you would like on work or other activities as a result of any emotional problems (such as feeling depressed or anxious)?" and "During the past 4 weeks have you not done work or other activities as carefully as usual as a result of any emotional problems (such as feeling depressed or anxious)?” Low scores in this domain suggest problems resulting from emotional problems. We were surprised that other SF-36 subscales were not related. Even the mental health composite score (a combination of the role emotional and mental health subscales) was not significantly related to recognition; thus, providers must be reacting to other aspects of patient presentation.

Indeed, our adjusted findings of better recognition for patients with heavy weighting of the $\mathrm{B}$ (persistent reexperiencing) or D (increased arousal) cluster symptoms support the notion that providers recognize these clusters as being cardinal for a diagnosis of PTSD. Providers may not pay as much attention to cluster $\mathrm{C}$ symptoms (persistent avoidance of stimuli associated with the traumatic event and numbing of general responsiveness) because these symptoms are more emotionally negative (as opposed to the positive nature of symptoms in clusters B and D). Patients also may further demonstrate avoidance by not showing up at appointments and being less apt to complain of symptoms in the $\mathrm{C}$ cluster or of PTSD in general. Furthermore, many of these $\mathrm{C}$ cluster symptoms are similar to depression symptoms. 
This article has focused on patient-level characteristics that might be associated with provider recognition of PTSD. We should also not overlook the fact that other factors could influence primary care providers' recognition and diagnosis of PTSD (and other psychiatric conditions). Providers' own training in diagnosis and management of psychiatric disorders and their comfort level in discussing psychiatric symptomatology with patients are clearly pertinent to their behavior in this area. Additionally, system-level factors, such as clinic organization, availability of ancillary staff to assist with case management details, case load expectations, and availability and use of screening tools may be related to the rate and accuracy of psychiatric diagnosis in primary care. While we were able to include a variable that examined the effects of hospital site (this variable was not significantly related to PTSD recognition), we were unable to examine any other provider- or clinic-level factors in this particular data set. Unfortunately, data for this project were collected prior to the advent of routine screening for military sexual trauma; therefore, we are unable to address the relationship of this exposure to PTSD and pain, which may have been particularly important for women. Our study was also conducted prior to implementation of universal PTSD screening in primary care. These new practices should aid primary care clinicians in detecting PTSD that previously would have gone unrecognized.

Patients whom we classified as having PTSD by CAPS but were not so diagnosed by their providers may have actually been in remission at the time of their clinic visits. Given the chronic nature of PTSD in most VA populations, this scenario is not likely, but we acknowledge it as a limitation. Strengths of our data include an independent assessment of PTSD, the large number of patients originally interviewed in primary care that yielded our CAPS-positive patients, the fact that we have a regionally representative sample with an oversample of women and large numbers of African American and elderly patients, and the 2-year time frame for examining recognition.

While the analysis has emphasized factors related to correct recognition of PTSD, we must also remember the converse of these analyses. The implication of these results is that providers tend not to consider a diagnosis of PTSD for patients who are not middle-aged, have not served in a war zone, do not have pain-related musculoskeletal conditions or substance use disorders, are not emotionally distressed, and do not show a predominance of B or D cluster symptoms. Thus, the characteristics of these unrecognized PTSD patients may not match the classic picture of PTSD in veterans. More rigorous screening to alert clinicians to these patients, as well as education about the full range of symptoms and traumatic exposures, may help to bring these overlooked patients to the attention of their providers so that their PTSD can be assessed and appropriately managed.

\section{ACKNOWLEDGMENTS}

This material was based on work partially supported by the VA Health Services Research and Development Service, grant VCR-99-010-2.

The authors have declared that no competing interests exist.

\section{REFERENCES}

1. Regier DA, Goldberg ID, Taube CA. The de facto US mental health services system: A public health perspective. Arch Gen Psychiatry. 1978;35(6):685-93.

2. Regier DA, Narrow WE, Rae DS, Manderscheid RW, Locke BZ, Goodwin FK. The de facto US mental and addictive disorders service system. Epidemiologic catchment area prospective 1-year prevalence rates of disorders and services. Arch Gen Psychiatry. 1993;50(2):85-94. [PMID: 8427558]

3. Bridges KW, Golberg DP. Somatic presentation of DSM III psychiatric disorders in primary care. J Psychosom Res. 1985;29(6):563-69. [PMID: 4087223]

4. Wilson DR, Widmer RB, Cadoret RJ, Judiesch K. Somatic symptoms. A major feature of depression in a family practice. J Affect Disord. 1983;5(3):199-207. [PMID: 6224832]

5. Magruder-Habib K, Zung WW, Feussner JR. Improving physicians' recognition and treatment of depression in general medical care. Results from a randomized clinical trial. Med Care. 1990;28(3):239-50. [PMID: 2179650$]$

6. Davidson JR, Weisler RH, Malik ML, Connor KM. Treatment of posttraumatic stress disorder with nefazodone. Int Clin Psychopharmacol. 1998;13(3):111-13. [PMID: 9690977]

7. Hankin CS, Spiro A 3rd, Miller DR, Kazis L. Mental disorders and mental health treatment among U.S. Department of Veterans Affairs outpatients: The Veterans Health Study. Am J Psychiatry. 1999;156(12):1924-30. [PMID: 10588406]

8. Stein MB, McQuaid JR, Pedrelli P, Lenox R, McCahill ME. Posttraumatic stress disorder in the primary care medical setting. Gen Hosp Psychiatry. 2000;22(4):261-69.

[PMID: 10936633] 
9. Taubman-Ben-Ari O, Rabinowitz J, Friedman D, Vaturi R. Post-traumatic stress disorder in primary-care settings: Prevalence and physicians’ detection. Psychol Med. 2001; 31(3):555-60. [PMID: 11305864]

10. Magruder KM, Frueh BC, Knapp RG, Davis L, Hamner MB, Martin RH, Gold PB, Arana GW. Prevalence of posttraumatic stress disorder in Veterans Affairs primary care clinics. Gen Hosp Psychiatry. 2005;27(3):169-79. [PMID: 15882763]

11. Frueh BC, Cusack KJ, Hiers TG, Monogan S, Cousins VC, Cavenaugh SD. Improving public mental health services for trauma victims in South Carolina. Psychiatr Serv. 2001;52(6):812-14. [PMID: 11376230]

12. Zatzick DF, Marmar CR, Weiss DS, Metzler T. Does trauma-linked dissociation vary across ethnic groups? J Nerv Ment Dis. 1994;182(10):576-82. [PMID: 7931206]

13. Kimerling R, Calhoun KS. Somatic symptoms, social support, and treatment seeking among sexual assault victims. J Consult Clin Psychol. 1994;62(2):333-40. [PMID: 8201071]

14. Schnurr PP, Spiro A 3rd. Combat exposure, posttraumatic stress disorder symptoms, and health behaviors as predictors of self-reported physical health in older veterans. J Nerv Ment Dis. 1999;187(6):353-59. [PMID: 10379722]

15. Wagner AW, Wolfe J, Rotnitsky A, Proctor SP, Erickson DJ. An investigation of the impact of posttraumatic stress disorder on physical health. J Trauma Stress. 2000;13(1): 41-55. [PMID: 10761173]

16. Jacobsen LK, Southwick SM, Kosten TR. Substance use disorders in patients with posttraumatic stress disorder: A review of the literature. Am J Psychiatry. 2001;158(8): 1184-90. [PMID: 11481147]

17. Keane TM, Wolfe J. Comorbidity in post-traumatic stress disorder: An analysis of community and clinical studies. J Appl Soc Psychol. 1990;20(21):1776-88.

18. Kilpatrick DG, Acierno R, Saunders B, Resnick HS, Best CL, Schnurr PP. Risk factors for adolescent substance abuse and dependence: Data from a national sample. J Consult Clin Psychol. 2000;68(1):19-30. [PMID: 10710837]

19. Schnurr PP, Spiro A 3rd, Paris AH. Physician-diagnosed medical disorders in relation to PTSD symptoms in older male military veterans. Health Psychol. 2000;19(1):91-97. [PMID: 10711592]

20. Jordan BK, Marmar CR, Fairbank JA, Schlenger WE, Kulka RA, Hough RL, Weiss DS. Problems in families of male Vietnam veterans with posttraumatic stress disorder. J Consult Clin Psychol. 1992;60(6):916-26. [PMID: 1460153]

21. MacDonald C, Chamberlain K, Long N, Flett R. Posttraumatic stress disorder and interpersonal functioning in Vietnam War veterans: A mediational model. J Trauma Stress. 1999;12(4):701-7. [PMID: 10646188]
22. Nezu AM, Carnevale GJ. Interpersonal problem solving and coping reactions of Vietnam veterans with posttraumatic stress disorder. J Abnorm Psychol. 1987;96(2):155-57. [PMID: 3584665$]$

23. Roberts WR, Penk WE, Gearing ML, Robinowitz R, Dolan MP, Patterson ET. Interpersonal problems of Vietnam combat veterans with symptoms of posttraumatic stress disorder. J Abnorm Psychol. 1982;91(6):444-50. [PMID: 7153418]

24. Brady KT. Posttraumatic stress disorder and comorbidity: Recognizing the many faces of PTSD. J Clin Psychiatry. 1997;58 Suppl 9:12-15. [PMID: 9329446]

25. Butler RW, Mueser KT, Sprock J, Braff DL. Positive symptoms of psychosis in posttraumatic stress disorder. Biol Psychiatry. 1996;39(10):839-44. [PMID: 9172704]

26. Falsetti SA, Resnick HS. Frequency and severity of panic attack symptoms in a treatment seeking sample of trauma victims. J Trauma Stress. 1997;10(4):683-89. [PMID: 9391951]

27. Goodman LA, Salyers MP, Mueser KT, Rosenberg SD, Swartz M, Essock SM, Osher FC, Butterfield MI, Swanson J; 5 Site Health and Risk Study Research Committee. Recent victimization in women and men with severe mental illness: Prevalence and correlates. J Trauma Stress. 2001; 14(4):615-32. [PMID: 11776413]

28. Hamner MB, Frueh BC, Ulmer HG, Huber MG, Twomey TJ, Tyson C, Arana GW. Psychotic features in chronic posttraumatic stress disorder and schizophrenia: Comparative severity. J Nerv Ment Dis. 2000;188(4):217-21. [PMID: 10789998]

29. Keane TM, Gerardi RJ, Lyons JA, Wolfe J. The interrelationship of substance abuse and posttraumatic stress disorder. Epidemiological and clinical considerations. Recent Dev Alcohol. 1988;6:27-48. [PMID: 3283857]

30. Southwick SM, Yehuda R, Giller EL Jr. Personality disorders in treatment-seeking combat veterans with posttraumatic stress disorder. Am J Psychiatry. 1993;150(7):1020-23. [PMID: 8317570]

31. Bair MJ, Robinson RL, Katon W, Kroenke K. Depression and pain comorbidity: A literature review. Arch Intern Med. 2003;163(20):2433-45. [PMID: 14609780]

32. Magruder KM, Yeager DE, Knapp R, Robinson RL. Is pain related to under-diagnosis of depression among primary care patients? In: Proceedings of the Annual Meeting of the American Psychiatric Association; 2007 May 25; San Diego, CA. Washington (DC): APA Press; 2007. p. 58.

33. Otis JD, Keane TM, Kerns RD. An examination of the relationship between chronic pain and post-traumatic stress disorder. J Rehabil Res Dev. 2003;40(5):397-405. [PMID: 15080224$]$

34. Asmundson GJ, Coons MJ, Taylor S, Katz J. PTSD and the experience of pain: Research and clinical implications of 
shared vulnerability and mutual maintenance models. Can J Psychiatry. 2002;47(10):930-37. [PMID: 12553128]

35. Villano CL, Rosenblum A, Magura S, Fong C, Cleland C, Betzler TF. Prevalence and correlates of posttraumatic stress disorder and chronic severe pain in psychiatric outpatients. J Rehabil Res Dev. 2007;44(2):167-78. [PMID: 17551871]

36. Sharp TJ, Harvey AG. Chronic pain and posttraumatic stress disorder: Mutual maintenance? Clin Psychol Rev. 2001;21(6):857-77. [PMID: 11497210$]$

37. Palyo SA, Beck JG. Post-traumatic stress disorder symptoms, pain, and perceived life control: Associations with psychosocial and physical functioning. Pain. 2005;117(1-2): 121-27. [PMID: 16099099]

38. Poundja J, Fikretoglu D, Brunet A. The co-occurrence of posttraumatic stress disorder symptoms and pain: Is depression a mediator? J Trauma Stress. 2006;19(5):747-51. [PMID: 17075919]

39. Jakupcak M, Osborne T, Michael S, Cook J, Albrizio P, McFall M. Anxiety, sensitivity and depression: Mechanisms for understanding somatic complaints in veterans with posttraumatic stress disorder. J Trauma Stress. 2006; 19(4):471-79. [PMID: 16929501]

40. Shipherd JC, Beck JG, Hamblen JL, Lackner JM, Freeman JB. A preliminary examination of treatment for posttraumatic stress disorder in chronic pain patients: A case study. J Trauma Stress. 2003;16(5):451-57. [PMID: 14584629]

41. Magruder KM, Frueh BC, Knapp RG, Johnson MR, Vaughan JA 3rd, Carson TC, Powell DA, Hebert R. PTSD symptoms, demographic characteristics, and functional status among veterans treated in VA primary care clinics. J Trauma Stress. 2004;17(4):293-301. [PMID: 15462536]

42. Grubaugh AL, Monnier J, Magruder KM, Knapp RG, Frueh BC. Female veterans seeking medical care at Veterans Affairs primary care clinics: Psychiatric and medical illness burden and service use. Women Health. 2006;43(3): 41-62. [PMID: 17194677$]$

43. Blake DD, Weathers FW, Nagy LN, Kaloupek DG, Klauminzer G, Charney DS, Keane TM. A clinician rating scale for assessing current and lifetime PTSD: The CAPS-1. Behav Therapist. 1990;13:187-88.

44. Weathers FW, Litz B. Psychometric properties of the Clinician-Administered PTSD Scale, CAPS-1. PTSD Res Q. 1994;5:2-6.
45. Weathers FW, Rusci AM, Keane TM. Psychometric properties of nine scoring rules for the Clinician-Administered Posttraumatic Stress Disorder Scale. Psychol Assess. 1999; 11(2):124-33.

46. Weathers FW, Litz BT, Herman JA, Huska JA, Keane TM. The PTSD Checklist (PCL): Reliability, validity and diagnostic utility. In: Proceedings of the 9th Annual Conference of the International Society of Traumatic Stress Studies; 1993 Oct; San Antonio, TX. Available from: http:// www.pdhealth.mil/library/downloadsPCL_sychometrics.doc

47. Yeager DE, Magruder KM, Knapp RG, Nicholas JS, Frueh BC. Performance characteristics of the posttraumatic stress disorder checklist and SPAN in Veterans Affairs primary care settings. Gen Hosp Psychiatry. 2007;29(4):294-301. [PMID: 17591505]

48. Blanchard EB, Jones-Alexander J, Buckley TC, Forneris CA. Psychometric properties of the PTSD Checklist (PCL). Behav Res Ther. 1996;34(8):669-73. [PMID: 8870294]

49. Stewart AL, Hays RD, Ware JE Jr. The MOS short-form general health survey. Reliability and validity in a patient population. Med Care. 1988;26(7):724-35. [PMID: 3393032]

50. Ware JE Jr, Sherbourne CD. The MOS 36-Item Short Form Health Survey (SF-36). I. Conceptual framework and item selection. Med Care. 1992;30(6):473-83. [PMID: 1593914]

51. Malik ML, Connor KM, Sutherland SM, Smith RD, Davison RM, Davidson JR. Quality of life and posttraumatic stress disorder: A pilot study assessing changes in SF-36 scores before and after treatment in a placebo-controlled trial of fluoxetine. J Trauma Stress. 1999;12(2):387-93. [PMID: 10378176]

52. Ware JE, Snow KK, Kosinski M, Gandek B. SF-36 ${ }^{\circledR}$ Health Survey: Manual and interpretation guide. Boston (MA): The Health Institute, New England Medical Center; 1993.

53. Cook JM, Elhai JD, Cassidy EL, Ruzek JI, Ram GD, Sheikh JI. Assessment of trauma exposure and post-traumatic stress in long-term care veterans: Preliminary data on psychometrics and post-traumatic stress disorder prevalence. Mil Med. 2005;170(10):862-66. [PMID: 16435760]

Submitted for publication June 21, 2007. Accepted in revised form January 14, 2008. 
